\title{
A Phytochemical Constituent, (E)-Methyl-Cinnamate Isolated from Alpinia katsumadai Hayata Suppresses Cell Survival, Migration, and Differentiation in Pre-Osteoblasts
}

\author{
Kyung-Ran Park ${ }^{1}$, Hanna Lee ${ }^{2}$, MyoungLae $\mathrm{Cho}^{2}$ and Hyung-Mun Yun ${ }^{1, *}$ \\ 1 Department of Oral and Maxillofacial Pathology, School of Dentistry, Kyung Hee University, Seoul 02453, \\ Korea; rudfks282@naver.com \\ 2 National Development Institute of Korean Medicine, Gyeongsan 38540, Korea; iiihanna@nikom.or.kr (H.L.); \\ meanglae@nikom.or.kr (M.C.) \\ * Correspondence: yunhm@khu.ac.kr; Tel.: +82-02-961-0691; Fax: +82-02-960-1457
}

Received: 15 April 2020; Accepted: 19 May 2020; Published: 24 May 2020

\begin{abstract}
Background: (E)-methyl-cinnamate (EMC), a phytochemical constituent isolated from Alpinia katsumadai Hayata, is a natural flavor compound with anti-inflammatory properties, which is widely used in the food and commodity industry. However, the pharmacological effects of methyl-cinnamate on pre-osteoblasts remain unknown. This study aimed to investigate the pharmacological effects and mechanisms of EMC in pre-osteoblast MC3T3-E1 cells (pre-osteoblasts). Methods: Cell viability and apoptosis were evaluated using the MTT assay and TUNEL staining. Cell migration and osteoblast differentiation were examined using migration assays, as well as alkaline phosphatase activity and staining assays. Western blot analysis was used to examine intracellular signaling pathways and apoptotic proteins. Results: EMC decreased cell viability with morphological changes and increased apoptosis in pre-osteoblasts. EMC also induced the cleavage of Poly (ADP-ribose) polymerase (PARP) and caspase-3 and reduced the expression of anti-apoptotic proteins. In addition, EMC increased TUNEL-positive cells in pre-osteoblasts, decreased the activation of mitogen-activated protein kinases, and suppressed cell migration rate in pre-osteoblasts. Subsequently, EMC inhibited the osteoblast differentiation of pre-osteoblasts, as assessed by alkaline phosphatase staining and activity assays. Conclusion: These findings demonstrate that EMC has a pharmacological and biological role in cell survival, migration, and osteoblast differentiation. It suggests that EMC might be a potential phytomedicine for treating abnormalities of osteoblast function in bone diseases.
\end{abstract}

Keywords: phytomedicine; Alpinia katsumadai Hayata; (E)-methyl-cinnamate; osteoblast; apoptosis; MAPKs

\section{Introduction}

Alpinia katsumadai Hayata is widely used in traditional Chinese medicine to treat emesis and gastric disorders [1]. The seeds of A. katsumadai have been used as an antioxidant and a stomachic [2]. It has been reported that they possess various bioactive compounds, including flavonoids, stilbenes, chalcones, monoterpenes, and sesquiterpenoids [3]. (E)-methyl-cinnamate (EMC), isolated from the seeds of A. katsumadai, is a methyl ester synthesized by cinnamic acid methyltransferase from cinnamic acid. Cinnamic acid is an antioxidant phytochemical agent and is known to be a safe flavoring used in the food industry $[4,5]$. The following pharmacological properties of EMC have been demonstrated: antibacterial and anti-fungal [6,7]. This includes being antispasmodic and myorelaxant 
for anti-neuropathic pain and anti-inflammatory effects [8,9]. EMC was also shown to inhibit adipocyte differentiation in 3T3-L1 cells [10]. However, there is no information on the pharmacological effects and biological actions of EMC in osteoblasts.

Osteoblasts are specialized cells derived from mesenchymal stem cells (MSCs) [11]. MSCs differentiate into osteoblasts via the Smad1/5/8 and Runt-related transcription factor 2 (RUNX2) pathways by osteogenic factors, such as BMP. Some osteoblasts are surrounded by the mineralized bone matrix and differentiate into osteocytes [11,12]. Apoptotic processes play critical roles in osteoblasts to maintain the mineralized and dynamic bone tissues in bone physiology and disease [13-15]. In addition, the migration and differentiation of osteoblasts into the region of bone formation are important for the synthesis and secretion of bone proteins, and the mineralization of bone tissues [16-18]. Therefore, the dysregulation of osteoblast function is etiologically important in several bone diseases, such as osteoporosis, osteopetrosis, and Paget's disease [14,19-21].

In the present study, we investigated the pharmacological and biological effects of EMC on apoptosis, migration, and differentiation in pre-osteoblast MC3T3-E1 cells (pre-osteoblasts).

\section{Results}

\subsection{EMC Decreases Cell Survival and Induces Morphological Changes in Pre-Osteoblasts}

(E)-methyl-cinnamate (EMC) was isolated from the seeds of $A$. katsumadai using HPLC to evaluate its effect on pre-osteoblasts. The structure and HPLC chromatogram of EMC are shown in Figure 1A,B. Pre-osteoblasts were initially treated with various doses of EMC for 24 and $48 \mathrm{~h}$. Cell proliferation was measured using the 3-[4,5-dimethylthiazol-2-yl]-2,5-diphenyltetrazolium bromide (MTT) assay. EMC significantly inhibited cellular proliferation in a time- and dose-dependent manner (Figure 2A,B). EMC also induced a morphologic change into small and protruding cell shapes with shrinkage in a dose-dependent manner (Figure 2C). Based on these results, moderate concentrations of EMC (10 and $30 \mu \mathrm{M}$ ) were selected to be used in all subsequent experiments.

A

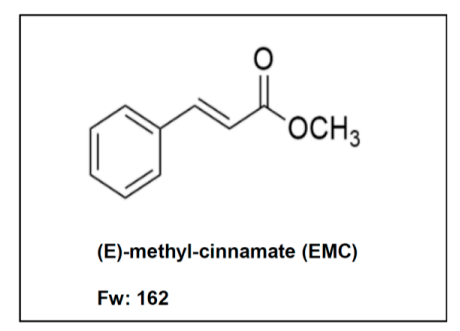

B

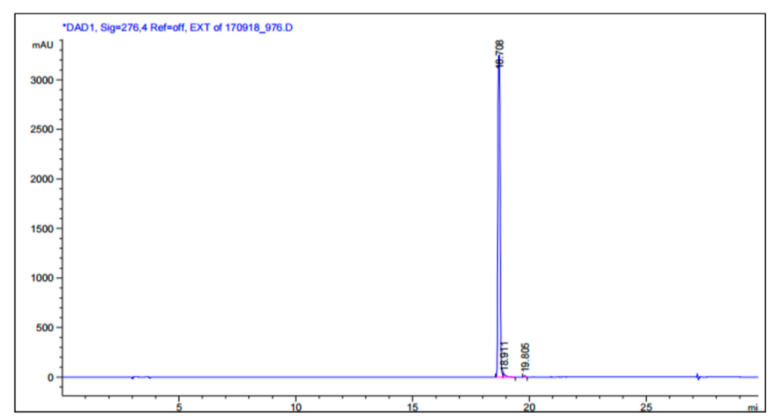

Figure 1. Chemical structure and High-performance liquid chromatography (HPLC) chromatogram of EMC. (A) Chemical structure of (E)-methyl-cinnamate (EMC) isolated from the seeds of Alpinia katsumadai Hayata. (B) HPLC chromatogram of EMC. The results are representative of three independent experiments. 
A

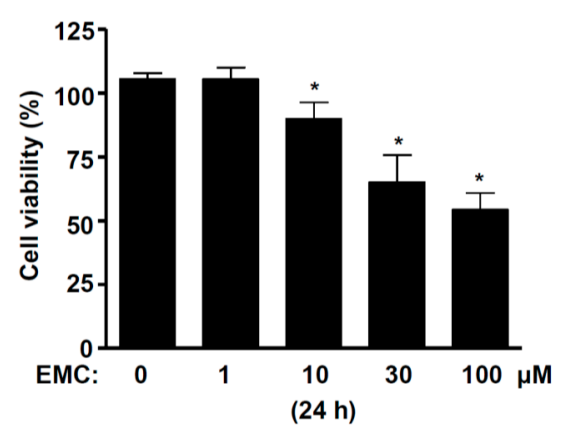

B

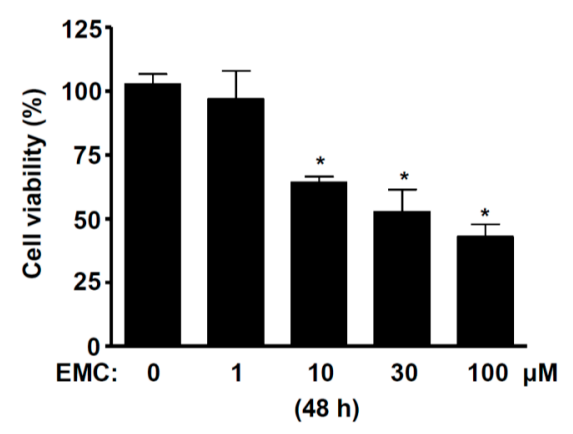

C

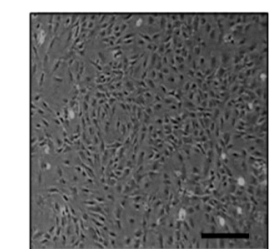

EMC:

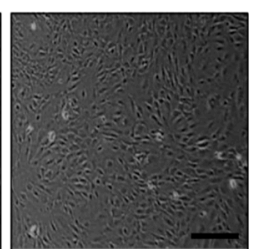

1

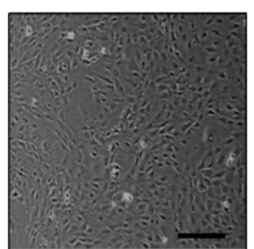

10

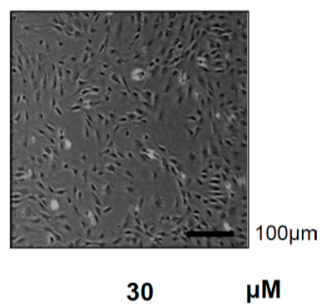

Figure 2. EMC decreases cell survival and induces morphological changes in pre-osteoblasts. (A,B) Pre-osteoblasts were treated with $\operatorname{EMC~(1,~10,~30,~and~} 100 \mu \mathrm{M})$ for $24 \mathrm{~h}(\mathrm{~A})$ and $48 \mathrm{~h}(\mathbf{B})$. Then, cell viability was measured by the MTT assay. (C) The morphological changes were observed under the phase contrast microscopy after treatment with EMC for $48 \mathrm{~h}$. The data are expressed as the mean \pm S.E.M. of experiments. ${ }^{*}(p<0.05)$ indicates statistically significant differences compared to the control.

\subsection{EMC Induces Apoptosis in Pre-Osteoblasts}

To determine whether the induction of apoptosis caused the inhibitory effects of EMC in pre-osteoblasts, we investigated the expression of apoptotic and anti-apoptotic proteins. EMC significantly increased the cleaved forms of poly (ADP-ribose) polymerase (PARP) and caspase-3 (Figure 3A-C), while it decreased the expression levels of Survivin and Bcl-2 (Figure 3D-F). We also demonstrated the process of apoptosis in pre-osteoblasts by EMC using the terminal deoxynucleotidyl transferase-mediated FITC-dUDP nick-end labeling (TUNEL) assay to detect DNA strand breaks and fragmentation. TUNEL-positive and DAPI-stained cells significantly increased in the presence of EMC in a dose-dependent manner (Figure 4A,B). 
A

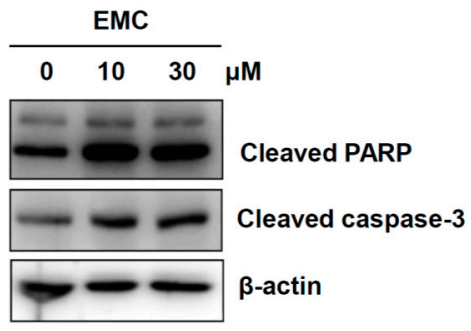

B

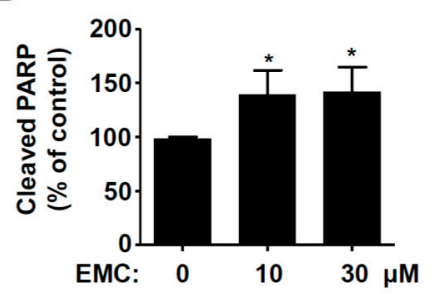

C

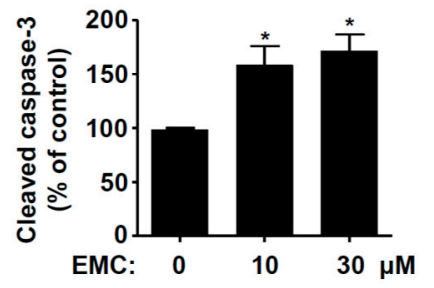

D

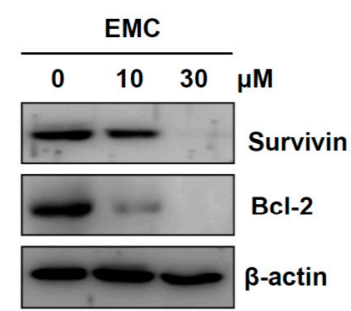

E

$\mathbf{F}$
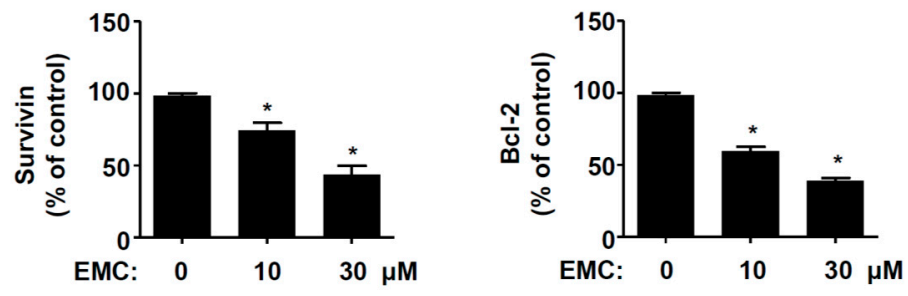

Figure 3. EMC induces apoptotic cell death in pre-osteoblasts. (A-C) Pre-osteoblasts were treated in the absence and presence of EMC for $24 \mathrm{~h}$. They were analyzed by western blot analysis with antibodies against the cleaved PARP and caspase-3 (A). $\beta$-actin was detected on the same sample to normalize the number of lysates. The levels of the cleaved PARP (B) and caspase-3 (C) were represented as relative percentages of the control. (D-F) The cells were analyzed by western blot analysis using Survivin and Bcl-2 antibodies (D). After normalization by $\beta$-actin, the levels of Survivin (E) and Bcl-2 (F) were represented as relative percentages of the control. The data are expressed as the mean \pm S.E.M. of experiments. ${ }^{*}(p<0.05)$ indicates statistically significant differences compared to the control. 
A

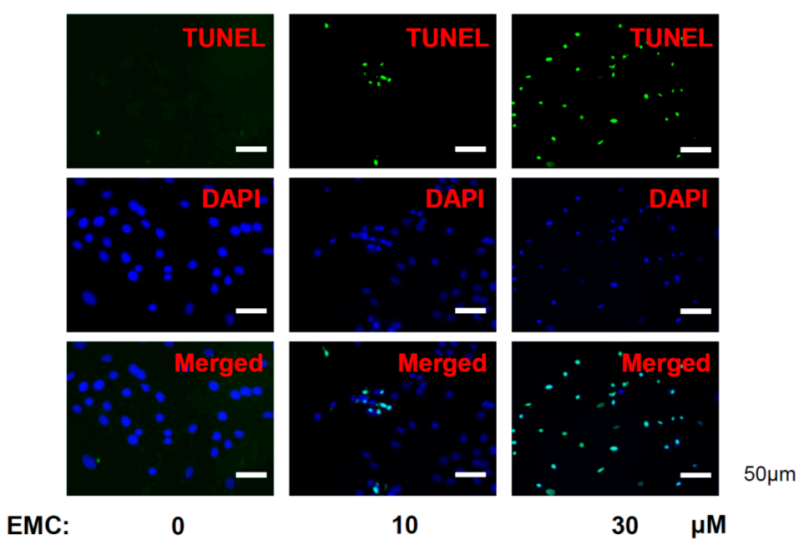

B

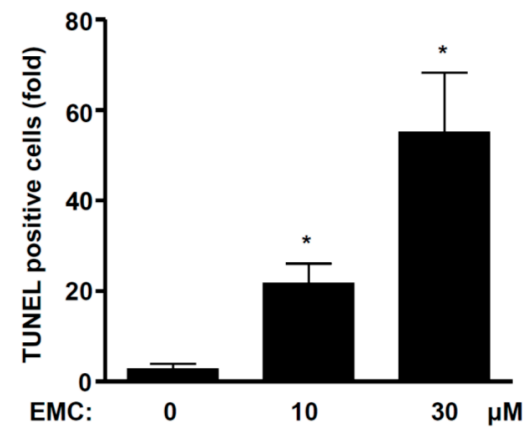

Figure 4. EMC increases DNA fragmentation in pre-osteoblasts. (A) DNA fragmentation was stained by TUNEL reaction (green) and DAPI (blue) solution at $24 \mathrm{~h}$ after EMC in pre-osteoblasts and observed by a confocal microscope. (B) The total number of cells in a given area was determined by DAPI staining. For quantification, three randomly selected areas were assessed. Scale bar: $50 \mu \mathrm{m}$. The results are representative of three independent experiments. The data are expressed as the mean \pm S.E.M. of experiments. ${ }^{*}(p<0.05)$ indicates statistically significant differences compared to the control.

\subsection{EMC Decreases MAPKs Signaling and Cell Migration in Pre-Osteoblasts}

Since the mitogen-activated protein kinases (MAPKs), including the ERK1/2, JNK, and p38 cascade prevent apoptosis, we examined the effects of EMC on the activity of MAPKs in pre-osteoblasts using western blot analysis. The results showed that EMC significantly inhibited the phosphorylation of ERK1/2 in a dose-dependent manner (Figure 5A.B). However, a significant phosphorylation reduction of JNK and p38 was exhibited only with $30 \mathrm{mM}$ EMC (Figure 5A,C,D). To investigate whether EMC affects the migration of pre-osteoblasts due to apoptosis, we performed a wound-healing migration assay. EMC significantly suppressed the cell migration rate in a dose-dependent manner (Figure 6A,B).

\subsection{EMC Suppresses the Osteoblast Differentiation of Pre-Osteoblasts}

To examine the effects of EMC on the osteoblast differentiation of pre-osteoblasts, we induced osteoblast differentiation using an osteogenic supplement medium (OS) containing $50 \mu \mathrm{g} / \mathrm{mL}$ L-ascorbic acid (L-AA) and $10 \mathrm{mM} \beta$-glycerophosphate ( $\beta$-GP) with EMC. The osteoblast differentiation was observed using Alkaline phosphatase (ALP) staining assays, a digital camera, and a colorimetric detector. EMC decreased the osteoblast differentiation induced by OS containing L-AA and $\beta$-GP (Figure 7A). The inhibition of osteoblast differentiation by EMC was also observed using a light microscope (Figure 7B). To validate these effects of EMC, we performed an ALP activity assay. EMC significantly decreased ALP activity under osteoblast differentiation in a dose-dependent manner (Figure 7C). 
EMC also suppressed the mRNA level of early and late osteogenic markers, ALP, osteocalcin (OCN), and osteopontin (OPN) (Supplementary Figure S1A-C).

A

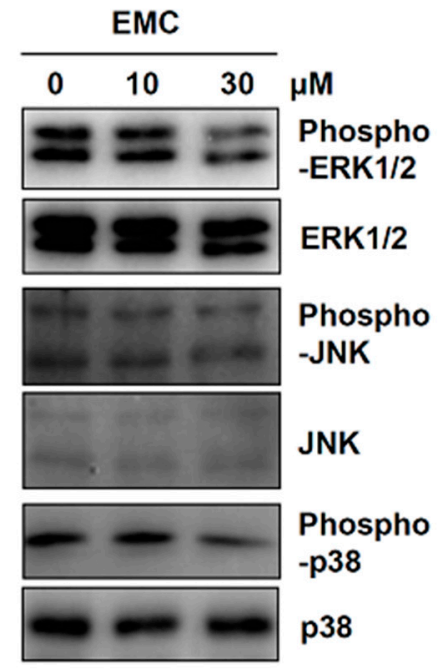

B

C

D
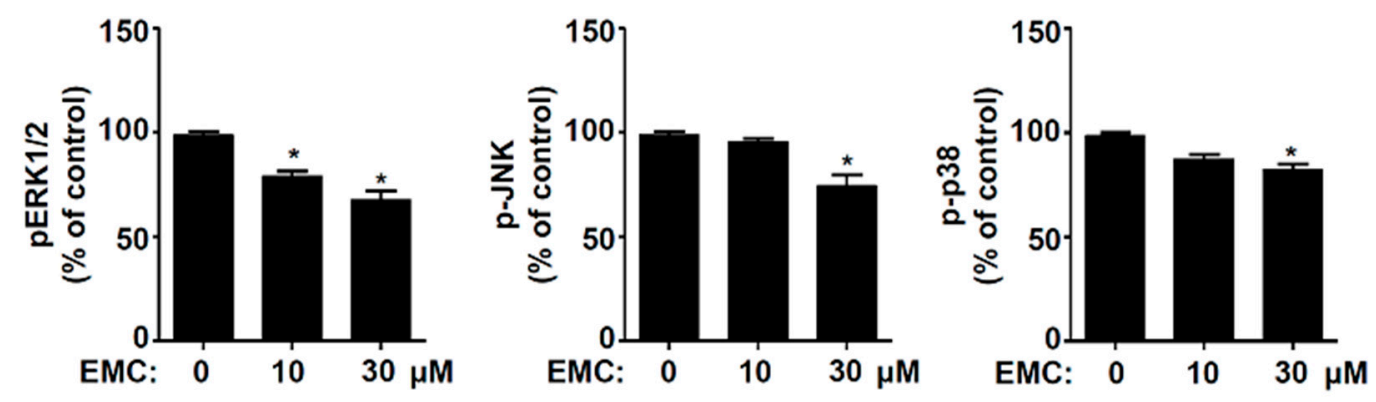

Figure 5. EMC decreases MAPKs signaling in pre-osteoblasts. (A-D) $24 \mathrm{~h}$ after EMC treatment, phoshpho-ERK1/2, ERK1/2, phospho-JNK, JNK, phospho-p38, and p38 were detected by western blot analysis. The levels of the phoshpho-ERK1/2 (B), phospho-JNK (C), and phospho-p38 (D) were represented as relative percentages of the control after normalization of the phosphorylation level by the total level (ERK1/2, JNK, and p38). The data are expressed as the mean \pm S.E.M. of experiments. * $(p<0.05)$ indicates statistically significant differences compared to the control. 
A
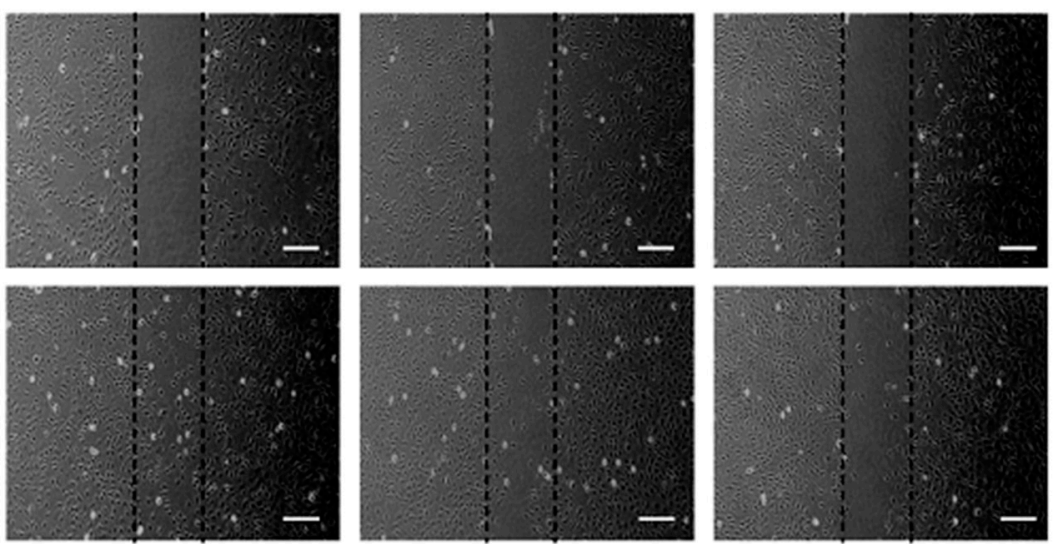

10

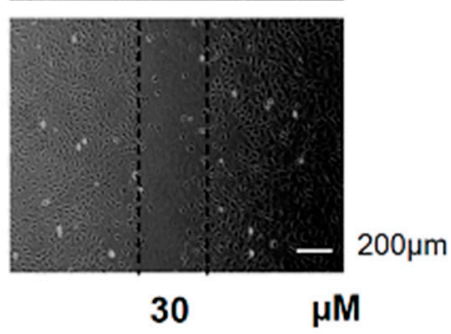

EMC:

0

30

$\mu \mathrm{M}$

\section{B}

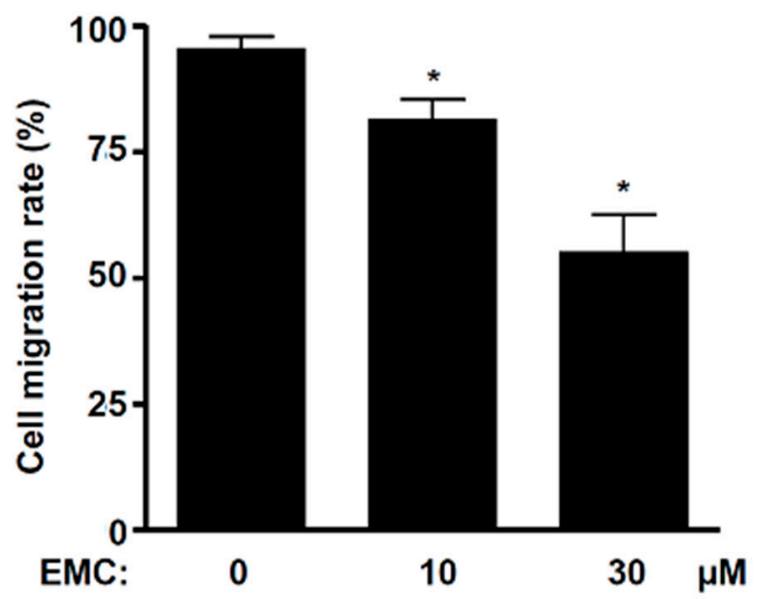

Figure 6. EMC reduces cell migration rate in pre-osteoblasts. (A,B) Pre-osteoblasts were treated with EMC for $24 \mathrm{~h}$. Then, cell migration was observed under the phase contrast microscopy (A), and cell migration rate (\%) was measured by tracing the area enclosing the spreading cell population. It was expressed as a bar graph normalized to the control. Scale bar: $200 \mu \mathrm{m}$. The results are representative of three independent experiments. The data are expressed as the mean \pm S.E.M. of the experiments. * $(p<0.05)$ indicates statistically significant differences compared to the control. 
A

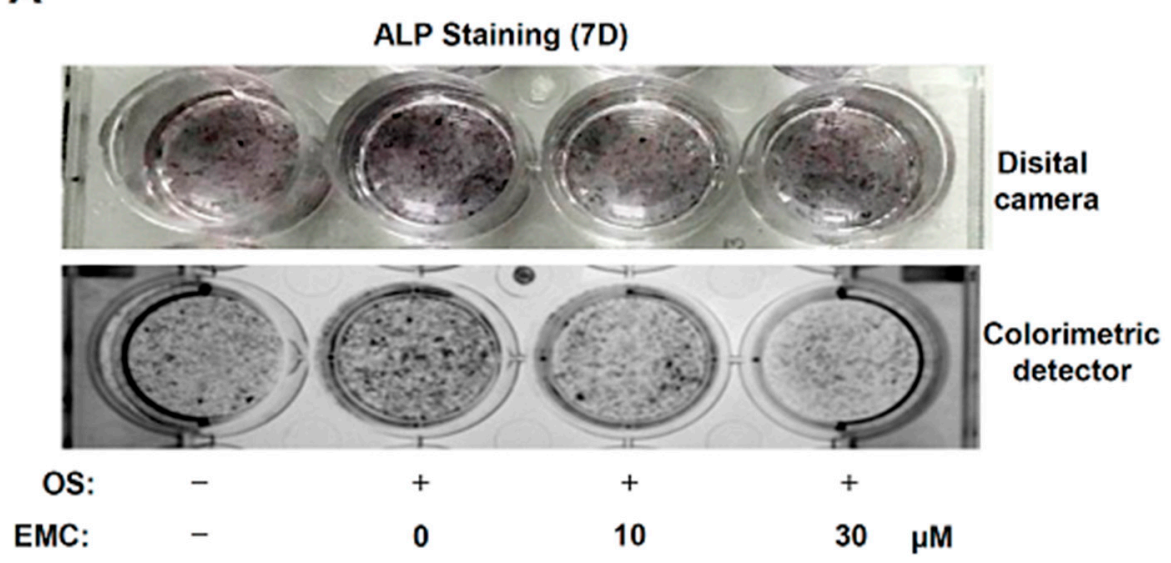

B

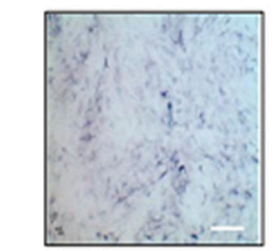

OS:

EMC:

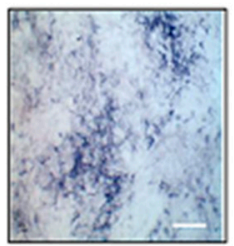

$+$

0

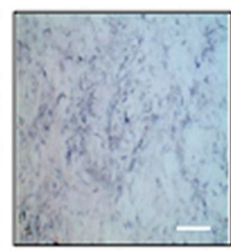

$+$

10

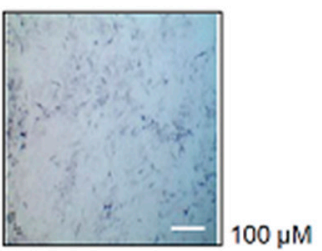

$+$

$30 \mu \mathrm{M}$

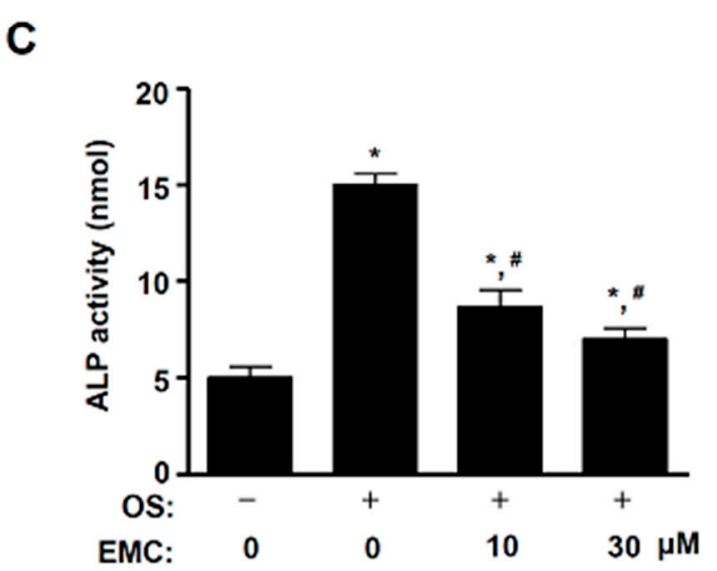

Figure 7. EMC suppresses the osteoblast differentiation of pre-osteoblasts. (A,B) Pre-osteoblasts were cultured in OS containing $50 \mu \mathrm{g} / \mathrm{mL}$ L-AA and $10 \mathrm{mM} \beta$-GP in the absence and presence of EMC for 7 days. Then ALP staining was observed by a disital camera (upper) and colorimetric detector (bottom) (A). The individual ALP-stained cells were detected using a light microscope (B). (C) Under the same condition, ALP activity was measured at $405 \mathrm{~nm}$ by the Multiskan GO Microplate Spectrophotometer. Scale bar: $100 \mu \mathrm{m}$. The results are representative of three independent experiments. The data are expressed as the mean \pm S.E.M. of experiments. ${ }^{*}(p<0.05)$ indicates statistically significant differences compared to the control. \# $(p<0.05)$ indicates statistically significant differences compared to the OS.

\section{Discussion}

Bone pathophysiology is regulated by the proliferation, apoptosis, migration, and differentiation of osteoblasts $[11,13,17]$. The impairment of osteoblast function causes several bone diseases, such as osteoporosis, periodontal disease, osteopetrosis, and Paget's disease [14,19-21]. Apoptosis is initially induced by the activation of caspase- 8 and -9 through the extrinsic death receptor pathway and the 
intrinsic mitochondrial pathway, leading to the activation of executioner caspase-3 [22]. The activation of caspase-3 leads to the cleavage of the DNA repair enzyme PARP that is critical in the apoptotic process [23]. In the present study, we found that EMC activates caspase- 3 and induces the cleavage of PARP in pre-osteoblasts. Activated caspase-3 also causes morphological changes, including cell shrinkage and chromatin condensation, and is governed by the Bcl-2 family and Survivin, which are considered anti-apoptotic components [22]. We also demonstrated that EMC downregulates Survivin and Bcl-2. It also induces apoptotic morphologic changes and DNA fragmentation in pre-osteoblasts. It was reported that caspase activity plays a crucial role in osteoblast apoptosis and survival, which affect bone development and metabolism. [24]. Our results suggest a critical role of EMC in regulating programmed cell death through apoptosis-related proteins in pre-osteoblasts.

Apoptotic cells lose the cell-to-cell adhesions, have reduced migration, and become separated from neighboring cells [22]. Cell migration and osteoblast differentiation also play an important role in bone metabolism and bone diseases [25]. The migration and differentiation of osteoblasts are required to form the appropriate shape of bones from the bone marrow, periosteum, surrounding tissues, and circulating blood [26]. In the present study, we demonstrated that EMC suppresses the migration rate of pre-osteoblasts and also inhibits the activation of ERK1/2, JNK, and p38. It was reported that the signaling of ERK1/2, JNK, and p38 controls cell proliferation, apoptosis, and migration. [27-30]. The migration and differentiation of osteoblast into bone tissue influences the synthesis, secretion, and calcium phosphate mineralization of the bone matrix [16-18]. We also demonstrated that EMC reduced ALP staining and activity during osteoblast differentiation. ALP is used as a marker of osteoblast differentiation since ALP is expressed early in bone development and is a key factor in the process of osteogenesis [31-33]. It was also reported that ALP expression is upregulated by the Smad1/5/8 and RUNX2 signaling pathways during osteogenesis [34,35]. Thus, our results suggest that EMC inhibits cell migration and osteoblast differentiation through the inactivation of ERK1/2, JNK, and $\mathrm{p} 38$, and the downregulation of ALP in pre-osteoblasts.

In conclusion, we originally reported evidence for the pharmacological effects and mechanisms of EMC isolated from the seeds of A. katsumadai in pre-osteoblasts. Our present results demonstrate that EMC increases cell apoptosis and decreases cell migration and osteoblast differentiation through the regulation of apoptotic signaling, and MAPKs and ALP activities in pre-osteoblasts. Our data also suggest that EMC might be a useful phytotherapeutic compound that could be used to treat abnormalities of osteoblast function in bone diseases.

\section{Materials and Methods}

\subsection{Plant Material}

The seeds of A. katsumadai were purchased from a commercial herbal market, Dongwoodang in Yeongcheon, Gyeongbuk, Korea, in March 2013. A voucher specimen (C537) has been deposited in the Natural Products Bank, National Institute for Korean Medicine Development (NIKOM).

\subsection{Extraction and Isolation of Methyl-Cinnamate}

The dried seeds of A. katsumadai $\left(10.0 \mathrm{~kg}\right.$ ) were extracted exhaustively with $80 \%$ ethanol (EtOH: $\mathrm{H}_{2} \mathrm{O}$ $=9: 1,24 \mathrm{~h} \times 2)$ at room temperature to yield the extract $(1.0 \mathrm{~kg})$. The crude extract was partitioned with water and organic solvents ( $n$-hexane, ethyl acetate, and $n$-butanol). Ethyl acetate (EtOAc)-soluble extract (300.0 g of $399.9 \mathrm{~g}$ ) was loaded on silica gel (70-230 mesh) open column chromatography with $n$-hexane/EtOAc (100:0 $\rightarrow$ 1:99, v/v; $500 \mathrm{~mL}$ each) to afford 10 subfractions (AKE 1 AKE 10). Subfraction AKE $2(670.0 \mathrm{mg})$ was separated by silica gel preparative HPLC and eluted with a gradient system of $n$-hexane/EtOAc (9:1 $\rightarrow 2: 8, v / v)$ to afford 10 subfractions (AKE 2-1 AKE 2-10) that were combined based on analytical HPLC analyses. Subfraction AKE 2-3 (133.0 mg) was separated using a Sephadex LH-20 column chromatography using methanol to yield six subfractions (AKE 2-3-1 AKE 2-3-6). The active compound ( $40.0 \mathrm{mg}$ ) was obtained from subfraction AKE 2-3-3 with gradient solvents 
of $\mathrm{MeOH} / \mathrm{H}_{2} \mathrm{O}(50: 50 \rightarrow$ 20:80, v/v). The structure of (E)-methyl-cinnamate (EMC) was elucidated by comparing the spectral data based on previous literature [3].

\section{3. (E)-Methyl-Cinnamate (EMC)}

Colorless amorphous powder; electron ionization mass spectrometer (EI-MS) $\mathrm{m} / z 162[\mathrm{M}]^{+}$; Molecular formula $\mathrm{C}_{10} \mathrm{H}_{10} \mathrm{O}_{2} ;{ }^{1} \mathrm{H}-\mathrm{NMR}\left(500 \mathrm{MHz}, \mathrm{CD}_{3} \mathrm{OD}\right) \delta 7.67(1 \mathrm{H}, \mathrm{d}, J=16.1 \mathrm{~Hz}, \mathrm{H}-7), 7.57(2 \mathrm{H}, \mathrm{m}$, $\mathrm{H}-2, \mathrm{H}-6), 7.38(3 \mathrm{H}, \mathrm{m}, \mathrm{H}-3, \mathrm{H}-4, \mathrm{H}-5), 6.50(1 \mathrm{H}, \mathrm{d}, \mathrm{J}=16.0 \mathrm{~Hz}, \mathrm{H}-8), 3.77\left(3 \mathrm{H}, \mathrm{s}, \mathrm{OCH}_{3}\right) ;{ }^{13} \mathrm{C}-\mathrm{NMR}$ (500 MHz, CD $\left.{ }_{3} \mathrm{OD}\right) \delta 169.1$ (C-9), 146.4 (C-7), 135.8 (C-1), 131.6 (C-4), 130.1 (C-2, C-6), 129.4 (C-3, C-5), $118.7(\mathrm{C}-8), 52.3\left(\mathrm{OCH}_{3}\right)$.

\subsection{Nuclear Magnetic Resonance (NMR)}

Nuclear magnetic resonance (NMR) experiments were performed on a JEOL ECX-500 spectrometer $\left({ }^{1} \mathrm{H}, 500 \mathrm{MHz} ;{ }^{13} \mathrm{C}, 125 \mathrm{MHz}\right.$; JEOL Ltd., Japan). All chemical shifts were referenced relative to the corresponding signals $\left(\delta_{\mathrm{H}} 3.31 / \delta_{\mathrm{C}} 49.15\right.$ for $\left.\mathrm{CD}_{3} \mathrm{OD}\right)$. EI-MS data were obtained using micromass spectrum (AUTOSPEC, UK). High-performance liquid chromatography (HPLC) was performed using the Agilent 1200 series (Agilent Technologies, CA, USA). Open column chromatography (CC) was carried out over a silica gel 60 (70-230 mesh, 230-400 mesh ASTM, Merck, Darmstadt, Germany) and sephadex LH-20 gel (GE Healthcare, Sweden). Pre-coated silica gel $60 \mathrm{~F}_{254}$ (Merck) were used for thin-layer chromatography (TLC).

\subsection{Culture of Pre-Osteoblast MC3T3-E1 Cells and Osteoblast Differentiation}

Pre-osteoblast MC3T3E-1 cells (\#CRL-2593) purchased from the American Type Culture Collection (ATCC) (Manassas, VA) were provided by the Bioevaluation Center (Korea Research Institute of Bioscience and Biotechnology, Republic of Korea). The cells were cultured in $\alpha$-minimum essential medium ( $\alpha$-MEM) without L-ascorbic acid (WELGEME, Inc., Republic of Korea) supplemented with $10 \%$ fetal bovine serum (FBS), penicillin (100 units $/ \mathrm{mL})$, and streptomycin $(100 \mu \mathrm{g} / \mathrm{mL})$ at $37^{\circ} \mathrm{C}$ in a humidified atmosphere of $5 \% \mathrm{CO}_{2}$ and $95 \%$ air. The differentiation of osteoblast was induced by changing the osteogenic supplement medium (OS) containing $50 \mu \mathrm{g} / \mathrm{mL}$ L-ascorbic acid and $10 \mathrm{mM}$ $\beta$-glycerophosphate (Sigma-Aldrich, St. Louis, MO). The medium was replaced every 2 days during the incubation period.

\subsection{MTT Assay}

Cell viability was measured using an MTT assay to detect NADH-dependent dehydrogenase activity as previously described in Reference [36].

\subsection{Western Blot Analysis}

Western blot analysis was carried out as previously described in Reference [37]. Briefly, equal amounts of proteins $(20 \mu \mathrm{g})$ transferred to a polyvinylidene fluoride (PVDF) membrane (Millipore, Bedford, MA) were blocked for $1 \mathrm{hr}$ at room temperature and incubated overnight at $4{ }^{\circ} \mathrm{C}$ with the specific primary antibodies. The membrane incubated with diluted horseradish peroxidase (HRP)-conjugated secondary antibodies (1:10,000, Jackson ImmunoResearch, West Grove, PA) for $2 \mathrm{~h}$ at room temperature was detected using the ProteinSimple detection system (ProteinSimple Inc., Santa Clara, CA).

\subsection{TUNEL Assay}

DNA fragmentation was examined using TUNEL. TUNEL assays were performed using the in situ Cell Death Detection Kit (Roche Diagnostics GmbH, Mannheim, Germany) according to the manufacturer's instructions [38]. For 4',6-diamidino-2-phenylindole (DAPI) (Sigma-Aldrich) staining, cells were incubated for $15 \mathrm{~min}$ at room temperature in the dark. TUNEL-positive and DAPI-stained 
cells were observed using a confocal microscope (K1-Fluo Confocal Laser Scanning Microscope, Republic of Korea).

\subsection{Cell Migration Assay}

Cell migration was assessed using an in vitro wound-healing assay [39]. The cells wounded with a $200 \mu \mathrm{L}$ pipette tip were incubated in the absence and presence of EMC for $24 \mathrm{~h}$ at $37^{\circ} \mathrm{C}$ in a humidified atmosphere of $5 \% \mathrm{CO}_{2}$ and $95 \%$ air. Cell migration was observed using a light microscope, and the cell migration rate was quantified.

\subsection{ALP Staining Assay}

Cells were washed with $1 \times$ PBS and then fixed in $10 \%$ formalin for $15 \mathrm{~min}$ at room temperature. After washing with distilled water, the cells were incubated with substrate solution for the reaction of ALP at $37^{\circ} \mathrm{C}$ for $1 \mathrm{hr}$, according to the manufacturer's protocol (Takara Bio Inc., Japan). The ALP staining was detected using a digital camera and colorimetric detector (ProteinSimple Inc., Santa Clara, CA).

\subsection{ALP Activity Assay}

The cell lysates were obtained using an alkaline phosphatase activity colorimetric assay kit (Biovision, Milpitas, CA) [36]. The absorbance was measured at $405 \mathrm{~nm}$ using the Multiskan GO Microplate Spectrophotometer (Thermo Fisher Scientific, Waltham, MA).

\subsection{Real-Time PCR Analysis}

Total RNA was extracted using the RNAqueous ${ }^{\circledR}$ kit and cDNA synthesized from $1 \mu \mathrm{g}$ of total RNA using the High Capacity RNA-to-cDNA kit (Applied Biosystems, Foster City, CA, USA) according to the manufacturer's protocol. Primers were as follows: ALP forward: 5'-ACACCTTGACTGTGGTTACT-3', ALP reverse: 5'-CCATATAGGATGGCCGTGAA-3', OCN forward: 5'-GAGGTGATAGCTTGGCTTAT-3', OCN reverse: 5'-TCCTTAGACTCACCGCTCTT-3', OPN forward: $5^{\prime}$-ACACCATGAGGACCATCTTT- $3^{\prime}$, OPN reverse: $5^{\prime}$-CGGAGTCTGTTCACTA CCTT- $3^{\prime}, \beta$-actin forward: $5^{\prime}$-AATGTGGCTGAGGACTTTGT- $3^{\prime}, \beta$-actin reverse: $5^{\prime}$-GGGACTT CCTGTAACCACTT-3'. Quantitative real-time PCR was performed using a 7500 Real-Time PCR System (Applied Biosystems).

\subsection{Statistical Analysis}

The data were analyzed using the Prism Version 5 program (GraphPad Software, Inc., San Diego, CA). All numeric values are presented as the means \pm S.E.M. The statistical significance of the data was determined using a Student's unpaired $t$-test. A value of $p<0.05$ was considered to indicate statistical significance.

Supplementary Materials: Supplementary materials can be found at http://www.mdpi.com/1422-0067/21/10/ 3700/s1. Figure S1. Effects of EMC on Osteoblast differentiation. (A-C) Pre-osteoblasts were differentiated with the indicated concentrations of EMC for 7 days, and total RNA was isolated. Osteoblast-specific early and late marker genes including ALP (A), OCN (B), and OPN (C) were analyzed by qRT-PCR. The values obtained for the target gene expression were normalized to $\beta$-actin. The data are expressed as the mean \pm S.E.M. of experiments. ${ }^{*}(p<0.05)$ indicates statistically significant differences compared to the control. \# $(p<0.05)$ indicates statistically significant differences compared to the OS.

Author Contributions: Conceptualization, K.-R.P. and H.-M.Y.; methodology, K.-R.P. and H.L.; software, K.-R.P.; validation, K.-R.P., H.-M.Y., and M.C.; formal analysis, K.-R.P.; investigation, K.-R.P.; resources, M.C.; data curation, K.-R.P.; writing - original draft preparation, K.-R.P.; writing—review and editing, H.-M.Y.; visualization, K.-R.P; supervision, H.-M.Y.; project administration, H.-M.Y.; funding acquisition, H.-M.Y. All authors have read and agreed to the published version of the manuscript.

Funding: This work was supported by the National Research Foundation of Korea [NRF] grant funded by the Korean government (MSIP) (NRF-2018R1D1A1B07043282). 
Acknowledgments: We appreciate the Bioevaluation Center (Korea Research Institute of Bioscience and Biotechnology, Republic of Korea) for their experimental assistance.

Conflicts of Interest: The authors declare no conflict of interest.

\section{Abbreviations}

$\begin{array}{ll}\text { ALP } & \text { Alkaline phosphatase } \\ \beta-G P & \beta \text {-glycerophosphate } \\ \text { EMC } & \text { (E)-methyl-cinnamate } \\ \text { L-AA } & \text { L-ascorbic acid } \\ \text { MAPKs } & \text { Mitogen-activated protein kinases } \\ \text { MSCs } & \text { Mesenchymal stem cells } \\ \text { MTT } & \text { 3-[4,5-dimethylthiazol-2-yl]-2,5-diphenyltetrazolium bromide (MTT) } \\ \text { OS } & \text { Osteogenic supplement } \\ \text { PARP } & \text { Poly (ADP-ribose) polymerase } \\ \text { RUNX2 } & \text { Runt-related transcription factor } 2\end{array}$

\section{References}

1. Lee, S.E.; Shin, H.T.; Hwang, H.J.; Kim, J.H. Antioxidant activity of extracts from Alpinia katsumadai seed. Phytother. Res. 2003, 17, 1041-1047. [CrossRef] [PubMed]

2. Nam, J.W.; Seo, E.K. Structural characterization and biological effects of constituents of the seeds of Alpinia katsumadai (Alpina Katsumadai Seed). Nat. Prod. Commun. 2012, 7, 795-798. [CrossRef] [PubMed]

3. Huang, W.; Yao, L.; He, X.; Wang, L.; Li, M.; Yang, Y.; Wan, C. Hypoglycemic activity and constituents analysis of blueberry (Vaccinium corymbosum) fruit extracts. Diabetes Metab. Syndr. Obes. 2018, 11, 357-366. [CrossRef]

4. Zhang, C.; Chen, X.; Crandall-Stotler, B.; Qian, P.; Kollner, T.G.; Guo, H.; Chen, F. Biosynthesis of methyl (E)-cinnamate in the liverwort Conocephalum salebrosum and evolution of cinnamic acid methyltransferase. Phytochemistry 2019, 164, 50-59. [CrossRef] [PubMed]

5. Bhatia, S.P.; Wellington, G.A.; Cocchiara, J.; Lalko, J.; Letizia, C.S.; Api, A.M. Fragrance material review on methyl cinnamate. Food Chem. Toxicol. 2007, 45, S113-S197. [CrossRef] [PubMed]

6. Shimoi, K.; Nakamura, Y.; Noro, T.; Tomita, I.; Fukushima, S.; Inoue, T.; Kada, T. Methyl cinnamate derivatives enhance UV-induced mutagenesis due to the inhibition of DNA excision repair in Escherichia coli B/r. Mutat. Res. 1985, 146, 15-22. [CrossRef]

7. Huang, Q.S.; Zhu, Y.J.; Li, H.L.; Zhuang, J.X.; Zhang, C.L.; Zhou, J.J.; Li, W.G.; Chen, Q.X. Inhibitory effects of methyl trans-cinnamate on mushroom tyrosinase and its antimicrobial activities. J. Agric. Food Chem. 2009, 57, 2565-2569. [CrossRef]

8. Lima, F.J.; Cosker, F.; Brito, T.S.; Ribeiro-Filho, H.V.; Silva, C.M.; Aragao, K.S.; Lahlou, S.; Souza, M.H.; Santos, A.A.; Magalhaes, P.J. Antispasmodic and myorelaxant effects of the flavoring agent methyl cinnamate in gut: Potential inhibition of tyrosine kinase. Eur. J. Pharmacol. 2014, 740, 192-199. [CrossRef]

9. Gui, Y.; Chen, L.; Duan, S.; Li, G.; Tang, J.; Li, A. Methyl cinnamate alleviated CCI-induced upregualtion of spinal AMPA receptors and pain hypersensitivity by targeting AMPK. Eur. J. Pharmacol. 2018, 833, 183-189. [CrossRef]

10. Chen, Y.Y.; Lee, M.H.; Hsu, C.C.; Wei, C.L.; Tsai, Y.C. Methyl cinnamate inhibits adipocyte differentiation via activation of the CaMKK2-AMPK pathway in 3T3-L1 preadipocytes. J. Agric. Food Chem. 2012, 60, 955-963. [CrossRef]

11. Fakhry, M.; Hamade, E.; Badran, B.; Buchet, R.; Magne, D. Molecular mechanisms of mesenchymal stem cell differentiation towards osteoblasts. World J. Stem Cells 2013, 5, 136-148. [CrossRef] [PubMed]

12. Bonewald, L.F. The amazing osteocyte. J. Bone Miner. Res. 2011, 26, 229-238. [CrossRef] [PubMed]

13. Hughes, D.E.; Boyce, B.F. Apoptosis in bone physiology and disease. Mol. Pathol. 1997, 50, $132-137$. [CrossRef] [PubMed]

14. Iguchi, M.; Hiroi, M.; Kanegae, H.; Ohmori, Y. Costimulation of Murine Osteoblasts with Interferon-gamma and Tumor Necrosis Factor-alpha Induces Apoptosis through Downregulation of Bcl-2 and Release of Cytochrome c from Mitochondria. Mediat. Inflamm. 2018. [CrossRef] [PubMed] 
15. Mollazadeh, S.; Fazly Bazzaz, B.S.; Kerachian, M.A. Role of apoptosis in pathogenesis and treatment of bone-related diseases. J. Orthop. Surg. Res. 2015, 10, 15. [CrossRef] [PubMed]

16. Karsenty, G.; Kronenberg, H.M.; Settembre, C. Genetic control of bone formation. Annu. Rev. Cell Dev. Biol. 2009, 25, 629-648. [CrossRef]

17. Zheng, X.; Dai, J.; Zhang, H.; Ge, Z. MicroRNA-221 promotes cell proliferation, migration, and differentiation by regulation of ZFPM2 in osteoblasts. Braz. J. Med. Biol. Res. 2018, 51, e7574. [CrossRef]

18. Karsenty, G.; Wagner, E.F. Reaching a genetic and molecular understanding of skeletal development. Dev. Cell 2002, 2, 389-406. [CrossRef]

19. Manolagas, S.C. Birth and death of bone cells: Basic regulatory mechanisms and implications for the pathogenesis and treatment of osteoporosis. Endocr. Rev. 2000, 21, 115-137.

20. Park, K.R.; Kim, J.Y.; Kim, E.C.; Yun, H.M.; Hong, J.T. RANKL-induced osteoclastogenesis is suppressed by 4-O-methylhonokiol in bone marrow-derived macrophages. Arch. Pharm. Res. 2017, 40, 933-942. [CrossRef]

21. Numan, M.S.; Amiable, N.; Brown, J.P.; Michou, L. Paget's disease of bone: An osteoimmunological disorder? Drug Des. Dev. Ther. 2015, 9, 4695-4707.

22. Elmore, S. Apoptosis: A review of programmed cell death. Toxicol. Pathol. 2007, 35, 495-516. [CrossRef] [PubMed]

23. Rosen, A.; Casciola-Rosen, L. Macromolecular substrates for the ICE-like proteases during apoptosis. J. Cell Biochem. 1997, 64, 50-54. [CrossRef]

24. Miura, M.; Chen, X.D.; Allen, M.R.; Bi, Y.; Gronthos, S.; Seo, B.M.; Lakhani, S.; Flavell, R.A.; Feng, X.H.; Robey, P.G.; et al. A crucial role of caspase-3 in osteogenic differentiation of bone marrow stromal stem cells. J. Clin. Investig. 2004, 114, 1704-1713. [CrossRef] [PubMed]

25. Iwaki, A.; Jingushi, S.; Oda, Y.; Izumi, T.; Shida, J.I.; Tsuneyoshi, M.; Sugioka, Y. Localization and quantification of proliferating cells during rat fracture repair: Detection of proliferating cell nuclear antigen by immunohistochemistry. J. Bone Miner. Res. 1997, 12, 96-102. [CrossRef] [PubMed]

26. Ichida, M.; Yui, Y.; Yoshioka, K.; Tanaka, T.; Wakamatsu, T.; Yoshikawa, H.; Itoh, K. Changes in cell migration of mesenchymal cells during osteogenic differentiation. FEBS Lett. 2011, 585, 4018-4024. [CrossRef]

27. Westhoff, M.A.; Serrels, B.; Fincham, V.J.; Frame, M.C.; Carragher, N.O. SRC-mediated phosphorylation of focal adhesion kinase couples actin and adhesion dynamics to survival signaling. Mol. Cell Biol. 2004, 24, 8113-8133. [CrossRef]

28. Chang, Y.M.; Shih, Y.T.; Chen, Y.S.; Liu, C.L.; Fang, W.K.; Tsai, C.H.; Tsai, F.J.; Kuo, W.W.; Lai, T.Y.; Huang, C.Y. Schwann Cell Migration Induced by Earthworm Extract via Activation of PAs and MMP2/9 Mediated through ERK1/2 and p38. Evid. Based Complement. Alternat. Med. 2011, 2011. [CrossRef]

29. Chen, Y.Y.; Liu, F.C.; Chou, P.Y.; Chien, Y.C.; Chang, W.S.; Huang, G.J.; Wu, C.H.; Sheu, M.J. Ethanol extracts of fruiting bodies of Antrodia cinnamomea suppress CL1-5 human lung adenocarcinoma cells migration by inhibiting matrix metalloproteinase-2/9 through ERK, JNK, p38, and PI3K/Akt signaling pathways. Evid. Based Complement. Alternat. Med. 2012, 2011. [CrossRef]

30. Liao, X.; Lu, S.; Zhuo, Y.; Winter, C.; Xu, W.; Wang, Y. Visualization of Src and FAK activity during the differentiation process from HMSCs to osteoblasts. PLoS ONE 2012, 7, e42709. [CrossRef]

31. Orimo, $\mathrm{H}$. The mechanism of mineralization and the role of alkaline phosphatase in health and disease. J. Nippon Med. Sch. 2010, 77, 4-12. [CrossRef] [PubMed]

32. Golub, E.E.; Harrison, G.; Taylor, A.G.; Camper, S.; Shapiro, I.M. The role of alkaline phosphatase in cartilage mineralization. Bone Miner. 1992, 17, 273-278. [CrossRef]

33. Yun, H.M.; Park, K.R.; Hong, J.T.; Kim, E.C. Peripheral serotonin-mediated system suppresses bone development and regeneration via serotonin 6 G-protein-coupled receptor. Sci. Rep. 2016, 6, 30985. [CrossRef] [PubMed]

34. Gaur, T.; Lengner, C.J.; Hovhannisyan, H.; Bhat, R.A.; Bodine, P.V.; Komm, B.S.; Javed, A.; van Wijnen, A.J.; Stein, J.L.; Stein, G.S.; et al. Canonical WNT signaling promotes osteogenesis by directly stimulating Runx2 gene expression. J. Biol. Chem. 2005, 280, 33132-33140. [CrossRef]

35. Phimphilai, M.; Zhao, Z.; Boules, H.; Roca, H.; Franceschi, R.T. BMP signaling is required for RUNX2-dependent induction of the osteoblast phenotype. J. Bone Miner. Res. 2006, 21, 637-646. [CrossRef]

36. Park, K.R.; Yun, H.M. RANKL-induced osteoclastogenesis in bone marrow-derived macrophages is suppressed by cisapride. Toxicology 2019, 422, 95-101. [CrossRef] 
37. Park, K.R.; Kim, E.C.; Hong, J.T.; Yun, H.M. Dysregulation of 5-hydroxytryptamine 6 receptor accelerates maturation of bone-resorbing osteoclasts and induces bone loss. Theranostics 2018, 8, 3087-3098. [CrossRef]

38. Park, K.R.; Yun, H.M.; Hong, J.T. G721-0282 inhibits cell growth and induces apoptosis in human osteosarcoma through down-regulation of the STAT3 pathway. Int. J. Biol. Sci. 2020, 16, 330-341. [CrossRef]

39. Sequeira, D.B.; Seabra, C.M.; Palma, P.J.; Cardoso, A.L.; Peca, J.; Santos, J.M. Effects of a New Bioceramic Material on Human Apical Papilla Cells. J. Funct. Biomater. 2018, 9, 74. [CrossRef]

(C) 2020 by the authors. Licensee MDPI, Basel, Switzerland. This article is an open access article distributed under the terms and conditions of the Creative Commons Attribution (CC BY) license (http://creativecommons.org/licenses/by/4.0/). 